Original Research Report

\title{
The Impact of the Digital Health Interventions in Curbing COVID-19 in Zimbabwe
}

\section{Stephen Chidhau ${ }^{1}$, Bismark Mutizwa ${ }^{1}$, Tinashe R Muzama ${ }^{1}$}

${ }^{1}$ University of Zimbabwe, Zimbabwe.

Article History

Received:

03.02.2021

Revised:

06.03.2021

Accepted:

09.03.2021

*Corresponding Author:

Bismark Mutizwa

Email:

bismarkmutizwa@gmail.com

This is an open access article, licensed under: $\mathrm{CC}-\mathrm{BY}-\mathrm{SA}$

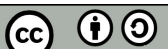

Abstract: Amid ongoing research about, Digital Health Interventions (DHI) in Zimbabwe, is the largely overlooked impact of DHI to mitigate the spread of COVID-19. To contribute towards filling this knowledge gap, the study seeks to examine the DHI strategies that have been adopted to curb the inimical effects of COVID-19 in Zimbabwe. DHI such as telemedicine, use of social media, Electronic Medical Records (EMRs), Mobile Health (mHealth), and Healthcare Information Systems (HIS) have been disposed to curtail the spread of COVID-19. The limitations and hurdles crippling DHI are discussed extensively. This study adopts a qualitative research design, comprising personal and targeted interviews and documentary review. Preliminary findings are that DHIs are effectively working for employing routine and innovative forms of Information and Communications Technology (ICT) to address health needs. However, the research noted that various factors such as corruption lack of funding, shortage of qualified workforce and medical expertise, and weak healthcare infrastructure are militating against robust deployment of DHIs. This study includes measures that can be adopted to address these challenges.

Keywords: COVID-19, Digital Health Interventions, E-Health, Impact. 


\section{Introduction}

According to the United Nations (UN) [1], in Zimbabwe the first case was recorded on March 20, 2020. Since then, the number of cases have been rising steadily. Though the outbreak is still evolving, the potential impact of intense community transmission remains high. The application of digital solutions in health for tracking and tracing the pandemic, data gathering, and analysis has become vital. The COVID-19 pandemic has created an urgent need for harmonious mechanisms to attend to the outbreak across health sectors, and Digital Health Interventions (DHIs) are being implemented to support the health response to COVID-19. DHIs which are being used includes telemedicine, use of social media, Electronic Medical Records (EMRs), Mobile Health (mHealth), and Healthcare Information Systems. The COVID-19 pandemic is occurring in an era of massive technological advancement and digital tools can effectively support institutions during a pandemic by facilitating the immediate widespread distribution of information, tracking transmission in real-time, creating virtual venues for day-to-day operations, and providing telemedicine visits for patients. Nonetheless, Zimbabwe is still struggling in implementing DHIs due to a myriad of reason for example corruption, lack of funding, shortage of qualified workforce and medical expertise, and weak healthcare infrastructure to mention but a few. To this end, this research seeks to interrogate the impact of DHI in curbing Covid-19 pandemic and offer viable remedial actions that can be adopted to overcome factors that are militating against robust implementation of DHIs.

The research is timely and worthwhile as it interrogates DHIs amidst the pandemic. It is equally important to note that studies on DHIs in curbing epidemics and pandemics in Zimbabwe are still mushrooming. Therefore, the research findings are likely going to help in future epidemic and pandemic management. This study will also contribute to the Health Sector by enriching the existing body of literature on digital interventions in addressing health delivery problems. Health care service providers shall benefit through this study as it seeks to explore their operations, examining challenges and opportunities. The study is also useful for information technology systems policymakers to advocate for digital-centred policies to improve access and effective health services delivery. The research also function as a springboard for future studies on DHIs, it seeks to stimulate interest among researchers and academia to interrogate the DHIs and proffer recommendations that add value to public administrators and the policy making machinery.

\section{Literature Review and Analytical Framework}

\subsection{Digital Health Interventions Defined}

Tracing the path of Digital Health (DH) /e-health evolution, Eysenbach [2] states that, the term was first used in the 1990s by health industry leaders and marketing people. They created and used DH to give an account of the new possibilities the internet is opening to the area of health care [3] [4] [5] [6] [7]. DH, sometimes called e-health, is an emerging field on the intersection of medical informatics, public health, and business, it refers to health services and information delivered or enhanced through the internet and related technologies [2]. The introduction of the internet has contributed to and transformed health information and health care delivery [7]. E-health established its paramount boost in 2004 after former US President George W. Bush broadcast an initiative to increase the adoption of Electronic Health Record System (EHRS) in the United States by 2014. According to Bush [8], "by computerising health records, we can avoid dangerous medical mistakes, reduce costs, and improve care." E-health, therefore, delivers new procedures for using health resources such as information, manpower, revenue, equipment, and supplies to produce requisite health care and service efficiently and effectively [9]. According to the Rockefeller Foundation [10], the ubiquity of e-health is demonstrated by breakthroughs in e-pharmacy projects in Malaysia, telemedicine networks in Bangladesh, and web-based communication systems to reduce maternal and child deaths in Peru amongst others.

However, the Ministry of Health of Ghana [11] says that computing equipment, multimedia systems, networking devices, imaging devices and internet systems, mobile telephony, and communication are the basis of ICT infrastructure in digital health. This position points out that ehealth goes further than the simple automation of health records and tele-consulting to all-inclusive automation of the healthcare system for effectual productivity. The outcomes considerably differ from Busagala and Kawono [12], who expressed that e-health is the presentation of information technology in the activities of a healthcare center. Investigating e-health shows Healy's definition 
more applicable since it takes into consideration factors such as IT system, human resource, and online procurement in the implementation of e-health at all healthcare set-ups.

As evident from various definitions and research perspectives, the central goal of DH is its contribution to quality healthcare, and the effective performance of the healthcare system. DH frameworks together with organisational changes and improvement of new skills can turn as key empowering instruments to encouraging critical upgrade in access to quality of care, and additionally proficiency and efficiency of the health care systems framework. Eysenbach, [2]states that, the "e" in e-health does not only stand for "electronic," but implies a number of other "e's," which together best characterise what e-health is all about and these include efficiency, enhancing quality, evidencebased, empowerment, encouragement, and education.

Moerman et al [13] state that e-health can be used to facilitate awareness campaigns on health matters and promote health initiatives. This can be done using various e-health solutions that include mobile health, telemedicine, and e-learning to minimise medical errors, promoting healthcare quality, reducing healthcare costs, and empower patients to take care of their medical needs. In this study, ehealth is classified as a wide variety of medical information and communication applications for enhanced healthcare service delivery and distribution of health-related data.

\subsection{Forms of Digital-Health Interventions (DHIs)}

Forms of Digital-Health Interventions (DHIs) comprises various applications that can potentially be used to address health care challenges. These include Electronic Medical Records (EMRs), Mobile Health (mHealth), Telemedicine, Consumer Health Informatics (CHI), and Healthcare Information Systems (HIS) among others.

Electronic Medical Records (EMR), also commonly referred to as Electronic Health Records (EHR) are applications that are used to keep the patient's clinical history and support medical activities by healthcare specialists. According to Anwar et al [14], EMRs include information such as laboratory results, treatment, and general patient medical history. Thus, electronic health records provide storage and facilitate communication of patient information among different healthcare specialists. Moreover, the caregivers can access the patient information electronically using certain authorisation.

Telemedicine is the sharing of medical data between two groups situated at various geographical locales employing a media transmission link [15]. Telemedicine includes video conferencing, where data exchange between health workers and patients is done via a video link. In the same context, Bhatia [16] refers to telemedicine as the application of ICT innovations to triumph over barriers such as physical and time constraints in the treatment of specific conditions. Telemedicine provides tertiary health care to people in remote areas through a virtual reduction in distance. Mbarika [17] asserts that used astutely, telemedicine can be an economic method in competence building, in the health care frameworks of several countries.

Health Information Systems (HIS) are systems used to gather, examine, maintain, retrieve, and evaluate health information [18]. WHO [19] notes that, a health management information system integrates all data and makes it available for use to improve and protect population health. It does so through collecting health data from the health and other relevant sectors and analyses it to ensure its overall quality and relevance and converts it into information for health-related decision-making. According to Lazaro [20], the objective of the Health Management Information System is to consistently check on the quality of service through comparing set standards and perception of service delivered.

Mobile Health denotes the use of mobile communications to improve healthcare service delivery [21]. The use of the internet and mobile devices has created new possibilities for health promotion and management. Moreover, these tools may be used to enhance access to various sources of knowledge for all parties including patients, health care providers, and the general population.

\subsection{COVID-19: Origin and Impact}

European Centre for Disease Prevention and Control [22] noted that:

"On 31 December 2019, a cluster of pneumonia cases of unknown aetiology was reported in Wuhan, Hubei Province, China. On 9 January 2020, China CDC reported a novel coronavirus as the causative agent of this outbreak, which is phylogenetically in the 
SARS-CoV clade. The disease associated to it is now referred to as novel coronavirus disease 2019 (COVID-19)."

Burrell [24] reinforced the above by asserting that, SARS-CoV-2 is a member of the family Coronaviridae and order Nidovirales. On January 30, 2020 the World Health Organisation (WHO) declared the outbreak as a Public Health Emergency of International Concern. On the 11th of March 2020, the WHO declared COVID-19 a pandemic. Since then, the pandemic has ravaged the world and its far-reaching effects have penetrated every boarder and airspace.

According to the Africa Center for Strategic Studies [25], the SARS-CoV-2 can mutate and its mutation has been detected in South Africa and the United Kingdom in December 2020 that make it significantly more transmissible raising prospects that the second wave is more dispersed. In South Africa, the mutated strain of the virus is dominant and driving the second wave to various African countries. This has seen a rise in cases and deaths in Zimbabwe. The impact of Covid-19 has been inimical and an impediment to growth and development. Mutizwa [23] and European Centre for Disease Prevention and Control [19] asserted that the pandemic has ushered the world in an unprecedented global recession. The US Congressional Research Services [26] propounded that:

"the pandemic is negatively affecting global economic growth beyond anything experienced in nearly a century. Estimates so far indicate the virus could trim global economic growth by $3.0 \%$ to $6.0 \%$ in 2020, with a partial recovery in 2021, assuming there is not a second wave of infections. The economic fallout from the pandemic raises the risks of a global economic recession with levels of unemployment not experienced since the Great Depression of the 1930s."

Equally, the African Union [27] established that:

"The European Union, the United States and Japan account for half of the world's GDP. These economies are based on trade, services and industries. However, measures to halt the pandemic have forced them to close their borders and drastically reduce economic activities; which will lead to recession in some of these developed economies. The Chinese economy accounts for about 16\% of the global GDP and it is the largest trading partner of most African countries and the rest of the world. The OECD forecasts a decline in economic growth rates for these major economies as follows: China 4.9\% instead of $5.7 \%$, Europe $0.8 \%$ instead of $1.1 \%$, the rest of the world $2.4 \%$ instead $2.9 \%$, with world GDP falling by 0.412 from the first quarter of 2020. UNCTAD forecasts downward pressure on foreign direct investment from $-5 \%$ to $-15 \%$. The International Monetary Fund has announced on the 23 March 2020 that investors have withdrawn US\$ 83 billion from emerging markets since the start of the crisis."

The world has also been robbed of the much-needed human capital with 2,177,685 deaths and $101,244,625$ cases as of 27 January 2021 (www.worldometres.info.coronavirus/). The measures suggested to mitigate the pandemic have indeed interrupted the transmission of the virus as projected by the Chinese experience. Nonetheless, for Mutizwa [23] it "comes with economic ramifications". This can be evidenced by the loss of incomes due to reduction in labour task forces, absenteeism increases at workplace culminating in low productivity [28]. The Zimbabwean economy is largely informal, International Labour Organisation (ILO) [29] argued that, approximately $80 \%$ of the population is in the informal sector. To this end, in as much as the implemented preventive measures slowed the transmission many families lost their source of income leaving them at the mercy of hunger and poverty. This has also negatively affected fiscal space and service delivery since majority of government revenues comes from the informal sector. The low investment in health system strengthening has resulted in shortages of essential health commodities, equipment, lack of reliable power and water supply, and low disposable income for the health workforce, amongst others. Equally important to note is the fact that, perceived risk of acquiring the virus has led many governments to implement a variety of digital control measures. 


\subsection{Digital Health Interventions in other Countries}

Various countries have adopted various (DHIs) to curb and manage the spread of COVID-19.

\section{Singapore}

The government of Singapore has progressively built up the digital infrastructure and engineering capabilities that enable it to respond to the COVID-19 pandemic. The government developed an app called Trace Together that is based on bluetooth signalling has been used to track patients infected with COVID-19. Singapore health authorities can track individuals and inform them if they have been in contact with a patient infected with COVID-19. According to Pymnts [30], the application uses a Bluetooth signal to connect. If a user is diagnosed with COVID-19, the application lets health authorities access their app data and see who else might have been affected. This patient monitoring system is beneficial in disease surveillance and outbreak management.

Also, Ask Jamie chatbot an app developed by GovTech as virtual assistant designed to answer queries within specific domains on Government agency websites. Launched in 2014, Ask Jamie has been implemented across 70 Government agency websites. Since 1 February 2020, the chatbot has been enhanced to address queries related to COVID-19, and uses machine learning to improve accuracy of the replies, and data analytics to detect trending topics.

\section{United Kingdom}

According to Jee [31] King's College London developed the COVID Symptom Tracker app, which aims to help patients monitor their symptoms. The applications help researchers and health practitioners get a better grasp of how the COVID-19 is spreading in certain areas, where hotspots are, and who is most at risk. The application helps in identifying why other patients have mild symptoms while others are critically ill. It helps detect the early warning of where symptoms are clustering and thus where outbreaks are starting. In addition to its benefits, the app can be used for research purposes to study the epidemiology of COVID-19. Also, the NHS COVID-19 app that can help public health efforts to stem the spread of the virus was introduced.

\section{Rwanda}

According to UNDP Rwanda [32] the Rwandan Ministry of Health acquired and deployed five smart anti-epidemic robots to contain the spread of COVID-19, with the support of UNDP Rwanda. They were immediately deployed to two treatment centres, and at the Kigali International Airport. The robots support detection of COVID-19 cases including among returning citizens, test patients, and provide other services in the hospitals. Designed with various advanced features, the robots will support doctors and nurses at the designated treatment centres and, in the future, at boarder points and other screening sites in Kigali and other provinces. Among other capabilities, the robots have the capacity to screen between 50-150 people per minute, deliver food and medication to patient rooms, capture data, and notify officers on duty about detected abnormalities for timely response and case management.

Also, Rwanda introduced Mbaza, a COVID-19 chatbot. The chatbot provides access to valuable COVID-19 information in plain language on any phone at any time and enables feedback connecting people to the authorities. It allows citizens to raise concerns and to provide governments with information on the local situation [32].

\section{Methodological Frameworks}

The study benefited from documentary reviews and key informant interviews. Various representatives from the Ministry of Health served as key informants, giving accurate information and discussing nitty-gritty issues on Digital-health. The study had a drawback in data gathering due to the traveling restrictions thus, to overcome this challenge telephone key informant interviews with health personnel from the ministry of health that are more vexed with Digital Health were conducted to provide ample evidence of the impact of Digital Health Interventions in mitigating the pandemic Zimbabwe. Through documentary review, the Zimbabwe's E-Health Strategy of 2012-2017 on DHI implementation was also examined.

\section{Discussion and Findings}

\subsection{DHIs in Zimbabwe}


The study learned that the role of DHIs to enhance disease surveillance, coordinate response mechanisms, and promote public awareness has become more significant. The government through the Ministry of Health Child Care (MHCC) has been bold in implementing disease containment measures to enhance preparedness in response to Covid-19 outbreak. The MHCC developed a National Preparedness and Response Plan (NPRP) that includes measures to increase capacity to detect, isolate and treat large numbers of cases, strengthen in-country laboratory capacities and ensure that health workers are protected from the transmission while managing cases. The NPRP was launched by the President on Tuesday, March 17, 2020 [25]. The government escalated its efforts through testing, tracing, and treatment with an institutional set-up for coordinating the emergency efforts that are consistent and adhering to the mechanisms and the global knowledge and experiences in response to Covid-19.

\section{The Bulk SMS Platform}

The use of apps and the bulk SMS Platform, a mechanism that delivers short messages over a mobile network in bulk is being used by the Ministry of Health in enabling communication without bias. The use of SMS platform has managed to inform health agencies to contact health workers remotely and to inform the public about the number of cases, symptoms, and prevention measures to curb the spread of COVID-19. According to Techzim [33], the MHCC joined hands with Econet and UNICEF to deliver information related to COVID-19 at no cost using SMS. The government is investing in, developed, strengthened, and supported digital health education mechanisms on Covid-19. A risk communication strategy for COVID-19 has been developed which incorporated standard messages for dissemination to key stakeholders, population groups, and the entire nation. There are targeted communication and advocacy campaigns that address social behaviour that can put people at risk and alleviative measures thereof. There is also the translation of messages into local languages, including sign language and broadcast widely for Radio, TV, and online platforms.

\section{SASAI Health Status Report}

Cassava Fintech International launched the SASAI Health Status Report (SHSR) as a secure blockchain technology-supported solution. The application enables users to record citizen's COVID19 status and enable them to share their testing results through digital platforms. The Health Status Report helps individuals and communities at large to get control of their lives and kickstart productivity as people get tested and can safely get back to work, while still observing the recommended public health and safety protocols. The Herald [34] stated that, these mechanisms can serve as useful resources to rapidly collect meaningful information on large cohorts of patients to study the evolution of their symptoms in real-time; this increase understanding of the different clinical phenotypes of people infected with COVID-19 and enabled the study of its long-term health consequences.

\section{Covid-19 Alert Reporting Management System}

Also, the Harare Institute of Technology (HIT) developed a Covid-19 Alert Reporting Management System (CAMS) to manage the recording of data [29]. The use of artificial intelligence has helped to combat the pandemic in developed countries in diagnosis, treatment, and drug discovery. The use of technology has also enabled these countries to quickly return to normal by easing lockdown restrictions. The power of digital and innovative technologies has also enabled other countries to continue doing business, utilising online trading, banking, and retailing among other activities. Integration of innovative digital solutions that develop online healthcare delivery models would enable public health systems to deal and be prepared for future pandemics.

\section{Broadband Partnerships}

In government hospitals, Africom Holdings partnered with Hellas Sat to assist the efforts of the Government of Zimbabwe in the fight against the spread of Covid-19 by providing free unlimited broadband connectivity to 127 public clinics and hospitals across the country. The project includes the provision of broadband connectivity over satellite as well as the integration of ICT for the provision of services to Hospitals and clinics. The partnership will ensure that information reaches the marginalised and also information can be collected giving the Covid-19 task force a good measure of information to feed their planning and mitigation [34] The benefits offered by this project and its 
impact on the operations of the hospitals and clinics is a great means for sustainability. The benefits for using them in combination with Sustainable satellite broadband Development will create the financial resources for the continuation of the project.

\section{The Health Management Information Systems}

The Ministry of Health uses the Health Management Information Systems (HMIS) as part of digital intervention to facilitate the pandemic response by enhancing surveillance and control activities (e.g. for rapid case reporting), and by facilitating the exchange of information (such as efficient documentation and sharing of patient records). The Systems Application Products (SAP) system at Chitungwiza Central Hospital helps health ministries to monitor a patient's situation, equipment, and medicine stocks, and provides a real-time dashboard with combined data. The statistics are updated to the nation periodically by the Ministry of Information and Broadcasting Services on the number of deaths, positive, recovered, and tasted cases.

\section{Strategic Information Project}

To support the MHCC in strengthening contact tracing and COVID-19 surveillance activities, International Centre for Aids and Treatment Program (ICAP), a global health leader executed the strategic information (SI) project funded by the U.S President's Emergency Plan for AIDS Relief (PEPFAR) through the U.S. Centres for Disease Control and Prevention (CDC). The aim was to incorporate electronic health record (EHR) systems at all main ports of entry to track and trace suspected COVID-19 cases among travellers in Zimbabwe. Call center systems were set up where members of the public can alert health care workers of possible COVID-19 cases in the community, leading to a quicker response time.

\section{Community Information Centres}

The government has an obligation to ensure that citizens are protected from misinformation by providing the public with facilities where they can access reliable, evidence-based information. Community Information Centres (CICs) are strategic in the fight against Covid-19 as they give communities access to accurate information about the virus on how to avoid contracting it and what to do when one is infected [33]. Zimbabwe is rolling out Community Information Centres in marginalised rural areas to ensure everyone has access to accurate COVI-19 information. Community Information Centres enable local communities to have access to Information Communication Technology (ICT) services at affordable rates so that members of the public can access reliable information on Covid-19 published by the WHO and the Ministry of Health and Child Care.

\section{New Variant Assessment Platform (Genomic Surveillance)}

The Government of Zimbabwe collaborated with the United Kingdom through the use of digital technologies to gain insight into Covid-19 and tackle its spread. According to The Herald [34], the genomic surveillance of SARS-CoV-2 is key in helping Zimbabwe understand and track the virus as it evolved, identify where the virus is coming from, how it is spreading, and inform public health control measures needed to limit its spread.

In response to the legion gaps identified in the public health management system exposed by the Covid-19, the government is in the process of setting up a National Public Health Research Institute meant to advice on best practices, appropriate values for scientific development, policy formulation and societal development.

\subsection{Factors Militating against Digital Health in Zimbabwe}

Many peculiar factors are impeding the progression of Digital-Health technologies in curbing Covid19. Zimbabwe's health system remains ill-prepared to deal with the pandemic. The research gathered through key informant interviews that the health system is beset by lack of essential equipment, inadequate medicines and medical supplies including personal protective equipment (PPE) for COVID-19. The major impediments to DHI delivery are inadequate ICT infrastructure, corruption, lack of knowledge and skill, lack of resources and lack of trained personnel to mention but a few. 


\section{Lack of ICT Infrastructure}

According to Sood et al., [35], professionals in various health facilities in Zimbabwe who implement e-Health solutions in are overwhelmed with the lack of ICT resources such as unavailability of computers and weak healthcare infrastructure. Health professionals in Zimbabwe have sounded the alarm over the country's limited capacity to test people for the new coronavirus, warning that a lack of critical equipment and infrastructure shortages may result in many cases going undetected (www.aljazeera.com). As of 18 August 2020, the country was conducting an average of 1200 diagnostic PCR tests per day This available data for Zimbabwe shows inadequate testing levels that do not meet the current capacity. World Report 2020 predicate that, there are still a lot of gaps to evaluate Zimbabwe's preparedness in managing Covid-19 because there are limited testing capacity, poor contact-tracing systems, lack of equipment to manage cases with severe disease in isolation and treatment centres), lack of PPE, staff shortage and human resources challenges, poor management of returnees in quarantine centres, weak and porous borders, corruption in Covid-19 supply tenders, among other issues.

\section{Lack of basic ICT knowledge/skills}

Most health professionals in Zimbabwe lack the basic ICT knowledge or skills that are needed to effectively use DHIs to curb COVID-19. This hampers the full utilisation of e-Health solutions by health professions. According to Marufu [36] the use of mobile phones by medical doctors in Zimbabwe for health care is relatively low. Small proportion of medical practitioners lack suitable information on how to access medical related internet research and suitable digital health solutions. The Information and Communication Technology system is not being fully exploited especially by the rural folks and the healthcare professionals who lack basic skills and knowledge.

\section{Financial Constrains}

Another factor, which encumbers Digital-Health in curbing COVID-19, is the issue relating to financial cost [25]. Zimbabwe has been in a long-lasting debt crisis for years. The health and economic impact of the pandemic aggravate the situation of the local population even more. KASA [37] added that, in April 2020, the G20, agreed on debt relief measures for 73 lower income countries in order to support them in fighting the impact of the pandemic. Zimbabwe was part of this list, but due to payment arrears to the World Bank, has been cancelled subsequently. The cancellation funding has a major negative impact on the implementation of digital technologies in Zimbabwe. The important major barrier to widespread COVID-19 testing in Zimbabwe has been the chronically underfunded health system. The testing has relied on donors from Jack Ma, The United States Centres for Disease Control and Prevention, and other partners who have made substantial contributions to the effort to boost the COVID-19 testing in Zimbabwe. A shortage of reagents and consumables, has hampered digital health in curbing COVID-19 in Zimbabwe which has severely impacted the service delivery.

\section{Corruption}

Corruption has remained a stumbling block, bedevilling the use of D H in Zimbabwe. The arrest of the former minister of health is a testimony that corruption is a major impediment in DHI implementation. According to Mutizwa [20] Obadiah Moyo, former Health Minister was charged with criminal abuse of office over the alleged awarding of a $\$ 60$ million contract for COVID-19 to Drax International LLC. This was in direct violation of Public Procurement and Disposal of Public Assets Act (Chapter 22:23) as Drax's ability to deliver was not assessed and the tender bidding process was not followed. Corruption contributes to a "drained financial system and a strained relationship with many development partners" Chilunjika [38], leading to a critical financing and funding gap with most partners focusing on humanitarian needs supporting the most immediate requirements of the people of Zimbabwe especially during this pandemic .

\section{Centralisation}

The testing of COVID-19 samples has remained centralised since its outbreak. At first samples from all provinces were sent to Harare, nevertheless, there has been a partial decentralisation as some provinces now have testing kits although some district hospitals and primary health care facilities are still sending their samples to the province. The centralisation of COVID-19 has been heavily criticised 
by citizens and health personnel [20].This trend has been due in part to persistent challenges with the procurement and supply of COVID-19 test kits. A shortage of reagents for PCR testing, has hampered COVID-19 testing in Zimbabwe [39]. The centralisation and low testing rate for Covid-19 has severely impacted the testing capacity, thereby impacting service delivery.

\section{International Isolation}

The study also discovered that international isolation is another challenge militating against digital health in Zimbabwe. Renovation and rejuvenation of dilapidating industries is impossible as sanctions are tailor-made to block every attempt of Zimbabwe to secure loans from the World Bank and IMF. Sanctions have also played a vital role in the "mass exodus" of Zimbabweans to other countries seeking greener pastures culminating in brain drain which negatively affects the human capital of the health sector [40]. The Covid-19 pandemic exacerbated the complexity of the situation in respect of the already existing humanitarian situation exhaling from sanctions. The voiding of sanctions would promote re-engagement and unleash economic growth and speed Zimbabwe's rehabilitation and renewal. The United Nations Secretary General António Guterres has urged for the lifting of sanctions on all countries, including Zimbabwe, in light of the COVID-19 outbreak as a move would allow for the access essential medical material required to fight the COVID-19 pandemic [41].

\section{Effects of COVID-19 in Zimbabwe}

The effects of Covid-19 in Zimbabwe are catastrophic and significant, ranging from disruptions in supply chains, inflationary pressures, compression in demand, a decline in trade in goods and services.According to UNDP [38] the Covid-19 pandemic hit Zimbabwe at a time when the country had targeted an economic rebound by inter alia, getting the economic fundamentals right through the implementation of the short-term Transitional Stabilisation Programme (TSP). The International Monetary Fund (IMF) has reported that the Covid-19 would make it even harder for the government to balance the policies needed to restore macroeconomic stability with those needed to address urgent social needs [38]. The Covid-19 measures pursue the rights to life, and access to health care, the scale of the lockdowns have resulted in unprecedented economic restrictions spawning widespread unemployment and poverty. There are no adequate measures with respect to the rights to food, shelter, livelihood, and security, leaving the populace in desperate circumstances as these closely related rights have major effect on the right to health itself. The Zimbabwean situation portrays problems of destitution in respect of the right to food (Zimstats 2019). The Lockdown Order, prohibiting the amassing of food at homes, is obscure, and given the monolithic food shortages and insecurity in the country, the regulation heightened food insecurity leaving the mass in poverty.

\section{Conclusion}

Digital health solutions provide the opportunity to buy time and human resources. As the COVID-19 pandemic is the first true global health crisis in the digital era, the study has observed there is a potential for the mushrooming of a plethora of digital solutions. While digital technologies offer tools for supporting a pandemic response, the Zimbabwean scenario is different as it is confronted by a myriad of challenges as reflected by the study. The emerging consensus is that, DHIs have an important role in response to outbreaks and pandemics, complementing conventional public-health measures, and thereby contribute to reducing the impact of COVID-19. This pandemic has demonstrated the helpfulness of DHIs. This creates a need for policymakers, researchers, and health practitioners to implement digital solutions into practice efficiently.

There is need for more concerted measures that addresses the most strategic needs of health professionals who plays a centripetal role on the COVID-19 crisis, are:

1. Government of Zimbabwe must invest more in digital health technologies.

More cooperative measures should be adopted to ensure that future digital health initiatives will have a greater impact on future epidemics and meet the most strategic needs to ease the life of people who are at the forefront of the crisis. The pandemic has brought to the fore the need to strengthen the health system. The government must ensure that outside of pandemics, DHI must be implemented into national health care systems in the long term. This would facilitate the use of DHI systems during outbreaks. Digital initiatives to fight COVID-19 should be relevant to both hospital and public health systems, adapted to the population, rapidly deployable and capable of evolving with the growth of the body of knowledge related 
to COVID-19. There must be connectedness of all the governmental and nongovernmental apps created during the COVID-19 pandemic to effectively activate interoperability across different technologies. This can lead to the creation of large, continuously updated data sets, which can be later used for diagnosis, management, and policy implementation.

2. The Government should spread awareness to all parts of the country through various communication strategies

There is a need to build public trust through various communication strategies across all digital channels and demonstrating a commitment to proportionate privacy. There is a need for a sustainable scale-up to ensure community literacy is increased, and to mobilise acceptance of testing information dissemination, preferably in vernacular languages, should be available via radio, TV, and accredited digital social media platforms. Online data and social media have had an ongoing, important role in public communication so there is need to make sure awareness on Zimbabwe reaches to remote areas around the country.

3. Training of health personnel

There is a need for extensive training to create a skilled workforce that understands health care, disease trends, information communication, and technology. An incentive that endorses Professional Development and encourages participating in digital health courses or seminars can be introduced in a means to increase knowledge in digital health among health workers.

4. Medical education should be made available so that training and exchange of information between doctors and other healthcare providers using digital technologies excel. This is one of the most frequent challenges among E-Health projects in health service delivery.

There is an urgent need to improve the healthcare services provided to all healthcare institutions.

5. The government must harness ICT as a key enabler in enhancing healthcare delivery.

The E-Health system should be operable and user friendly at the same time accessible, reliable, available, and timely to both the health professionals and patients. In this process, the government must partner with various organisations as stakeholders since the implementation of such a system is a tall order. According to WHO [39] "to improve health and reduce health inequalities, rigorous evaluation of E-Health is necessary to generate resources and promote the appropriate integration and use of technologies." While recognising the innovative role that digital technologies can play in strengthening the health system, there is an equally important need to evaluate their contributing effects and ensure that such investments do not inappropriately divert resources from alternative, non-digital approaches.

6. The government must align the education policy and the ICT policy to promote the appropriate integration and use of technologies.

Despite having a National ICT strategy that realises the importance of digital health interventions in health-care delivery, both public and private sectors should be joined to ensure that there are cooperation and coordination and the practical actualisation of the realisation of E-Health. The in-ward focus in ICT adoption should prove to be a significant platform where health-care centres should start working for driven patient experience in the future.

\section{References}

[1] UN, "COVID-19-CO Response/UN-Zimbabwe COVID19 Socio-economic Framework Final," 2020 [Online]. Available: www.undp.org/content/dam/rba/docs/COVID-19Response/UN-ZimbabweCOVID-19-Socio-economic-Framework-Final.pdf. [Accessed 2020].

[2] G. Eysenbach, "What is e-health: Time for an Update?," Journal of Medical Internet Research, vol. 3, no. 2, pp. 20-21, 2001.

[3] S.M. Govender and M. Mars, "The use of tele-health services to facilitate audiological management for children: A scoping review and content analysis," Journal of Telemedicine and Tele-care, vol. 23, no. 3, pp. 392-401, 2016. 
[4] A. S. Abdulbaqi, S. M. Nejrs, S. D. Mahmood and I. Y. Panessai, "A Tele Encephalopathy Diagnosis Based on EEG Signal Compression and Encryption", in International Conferences of ACeS 2020, Dec. 2020.

[5] A. S. Abdulbaqi, E. S. Yousif, M. N. Saif Al-din and I. Y. Panessai, "Virtual Environments Utilization for ECG Signals Analysis and Evaluation: Towards Heart Condition Assessment", in IOP Conference Series: Materials Science and Engineering, vol. 928, 2nd International Scientific Conference of Al-Ayen University (ISCAU2020), 15-16 July 2020.

[6] I. Y. Panessai, and A. S. Abdulbaqi, "An efficient method of EEG signal compression and transmission based telemedicine," Journal of Theoretical and Applied Information Technology, vol. 97, no. 4, pp. 1060-1070, 2019.

[7] H. Rippen, "Risk A. eHealth Code of Ethics," Journal of Medical Internet Research, vol. 2 , no. $2,2000$.

[8] G. W Bush, "Transforming Health Care: The President's Health Information Technology Plan,” 2004 [Online]. Available: www.georgewbush-whitehouse.archives. gov/infocus/technology/economic_policy200404/chap3.html. [Accessed: 2020].

[9] M. Jin and J. Kim. "Development and Evaluation of an Evaluation Tool for Healthcare Smartphone Applications," TelemedicineJournal and E-health, vol. 21, no. 10, pp. 831-3, 2015.

[10] Rockerfeller Foundation, "From Silo to System: An Overview of ehealth's transformative power, 2010 [Online]. Available: www.rockerfellerfoundation.org. [Accessed: September 2020].

[11] Ministry of Health, "Ghana E-Health Strategy -National E-Health Strategy," 2010 [Online]. Available: http://www.moh-ghana.org [Accessed: July 2020].

[12] A. Busagala and M. Kawono, "Underlying Challenges of E-Health Adoption in Tanzania," International Journal of Information and Communication Technology Research, vol. 3, no. 1, pp. 40-48, 2013.

[13] A. H. Moerman, T. M. Cornelis, and S.M. Helianthe "An explorative Delphi study to uncover knowledge, attitudes for nurses and skills for nurses using eHealth," Journal of Ehealth, vol. 3, no. 1, 2014.

[14] F. Anwar, A. Shamimc and S. Khan, "Barriers in implementation of health information technology in developing societies," International Journal of Advanced Computer Science, vol. 2, no. 1, 2012.

[15] World Health Organisation, "Health Information Systems," 2008 [Online]. Available: https://www.who.int/healthinfo/statistics/toolkit_hss/EN_PDF_Toolkit_HSS_Informati onSystems.pdf. [Accessed: July 2020].

[16] J. S. Bhatia, "Adoption of Telemedicine in India- An Exploratory Study," International Journal of Emerging Technology and Advanced Engineering, vol. 4, no. 10, 2014.

[17] V. Mbarika, M. Kituyi, A. Rwashana, and R. Isabalija, "A Framework for Designing Sustainable Telemedicine Information Systems in Developing Countries," Emerald Journal of Systems and Information Technology, Issue 3, May/June, 2012 .

[18] R. C. Alvarez, "The promise of e-Health - a Canadian perspective". E-Health International, vol. 1, no. 1, pp. 1476-3591, 2002.

[19] World Health Organisation, "Program and Project: Publication: Global Observatory for eHealth,” 2010 [Online]. Available: http://whqlibdoc.who.int/publications/2011/9789 241564168 eng.pdf [Accessed: September 2020].

[20] Lazaro, "Underlying Challenges of E-Health Ado, the in Tanzania," International Journal of Information and Communication Technology, 2013.

[21] C. Avgerou, "The significance of context in information systems and organisational change," Information Systems Journal, vol. 11, no. 1, pp. 43-63, 2001. 
[22] European Centre for Disease Prevention and Control. Outbreak of novelcoronavirus disease 2019 (COVID-19): increased transmission globally-fifth update, 2 March 2020. Stockholm: ECDC, 2020.

[23] B. Mutizwa, "COVID-19 a Global Nightmare: Revamping the Zimbabwean Health Sector (ZHS) For Future Epidemic and Pandemic Management," Journal of African Problems and Solutions, vol. 2, no. 1, pp. 59-73, 2020.

[24] C. Burrell, C. Howard and F. F. Murphy, White's medical virology (5 ${ }^{\text {th }}$ Ed). United States: Academic Press, 2016.

[25] Africa Center for Strategic Studies, "Analysing Africa's Second Wave of COVID-19," 2020 [Online]. Available: africacenter.org/spotlight/analyzing-africas-second-wave-ofCovid-19/. [Accessed 2020].

[26] Congressional Research Services, Global Economic Effects of COVID-19. Washington DC: Congress Research Services, Center for Systems Science and Engineer, 2020.

[27] African Union, Impact of Coronavirus (COVID-19) on the African Economy. Addis Ababa, 2020.

[28] A. Delivorias, and N. Scholz, "Economic impact of epidemics and pandemics," European Union Parliamentary Research Services, 2020.

[29] ILO, Women and Men in the Informal Economy: A Statistical Picture, Employment Sector. Geneva: International Labour Office, 2020.

[30] Payments News \& Mobile Payments Trends, "App Lets Singapore Track Virus Patients' Movements," 2020 [Online]. Available: https:/www.pymnts.com/corona virus/2020/app-lets-singapore-track-virus-patients-movements/ [Accessed: September 2020].

[31] Jee C. MIT Technology Review, “A new app might help researchers monitor the spread of coronavirus," March 2020 [Online. Available: https:/www.technologyreview.com/ 2020/03/25/950310/a-new-app-might-help-researchers-monitor-the-spread-ofcoronavirus/. [Accessed: 2020].

[32] Techzim "POTRAZ Chairman speaks on the role of tech in Zimbabwe after COVID19," 2020 [Online]. Available: https://www.techzim.co.zw/2020/10/potraz-chairmanspeaks-on-the-role-of-tech-in-zimbabwe-after-Covid-19/. [Accessed: 2020].

[33] The Herald Covid-19, "Leveraging on ICTs," 2020 [Online]. Available: https:// www.herald.co.zw/Covid-19-leveraging-on-icts/ [Accessed: July 2020].

[34] The Herald Zim, "UK scientists in Covid-19 collaboration," 2020 [Online]. Available: https://www.herald.co.zw/zim-uk-scientists-in-Covid-19-collaboration/. [Accessed: 2020].

[35] S. P. Sood, S. N. Nwabueze, V. W. A. Mbarika, N. Prakash, S. Chatterjee, P. Ray, and S. Mishra, "Electronic medical records: a review comparing the challenges in developed and developing countries." In Hawaii International Conference on System Sciences, Proceedings of the 41st Annual, pp 248-248, 2008.

[36] C. Marufu, and K.A. Mabo, "Utilisation of mobile health by medical doctors in a Zimbabwean health care facility," health sa gesondheid vol. 22, pp. 1, pp. 228-234, 2017.

[37] Kirchliche Arbeitsstelle Südliches Afrika (KASA), "Zimbabwe and the COVID-19 and debt crisis: Causes and solutions 2020," 2020 [Online]. Available: https://www. kasa.de/veranstaltungen/detail/?tx_calendarize_calendar\%5Bindex $\% 5 \mathrm{D}=213 \& \mathrm{cHash}=7$ af4e9181719413c38d9324adbec9d45. [Accessed: 2020].

[38] A. Chilunjika, "From corporate mess to corporate hygiene: Dealing with corruption in Zimbabwe's public sector," Journal of Public Administration and Development Alternatives (JADA), vol. 3, no. 2, pp. 52-72, 2018.

[39] Mananavire B, "Zimbabwe: COVID-19 bombshell-Zim test kits run out," 2020 [Online]. Available: https://allafrica.com/stories/202005220106.html. [Accessed 2020]. 
[40] A. Chilunjika, and B. Mutizwa, "Exploring factors militating against the performance of parastatals in Zimbabwe: the case of the national railways of Zimbabwe from 2008 to 2016" Journal of Public Administration and Development Alternatives (JPADA), vol. 4, no. 2, pp. 41-60, 2019.

[41] Allafrica, "COVID-19 Crisis Is the Time to Ease Sanctions on Zimbabwe - UN," 2020 [Online]. Available: https://allafrica.com/view/group/main/main/id/00072658.html. [Accessed: 2020]. 